\title{
The non-reverse transcriptase activity of the human telomerase reverse transcriptase promotes tumor progression (Review)
}

\author{
YONG QIN, HONG GUO, BO TANG and SHI-MING YANG \\ Department of Gastroenterology, Xinqiao Hospital, Third Military Medical University, \\ Chongqing 400037, P.R. China
}

Received February 14, 2014; Accepted April 17, 2014

DOI: $10.3892 /$ ijo.2014.2470

\begin{abstract}
In human cancer, high expression of telomerase is correlated with tumor aggressiveness and metastatic potential. Human telomerase reverse transcriptase (hTERT), which regulates telomere length, can promote tumor development. Most research on hTERT has been focused on its crucial function of telomere maintenance. However, there are many phenomena that cannot be explained by its reverse transcriptase activity. Accumulating evidence suggests that hTERT has functions independent of its protective function at the telomere ends, such as increasing the anti-apoptotic capacity of cells, enhancing DNA repair, maintaining stem cells and regulating gene expression. This review will provide an update on the nonreverse transcriptase activity of hTERT and its contribution to tumor formation, metastasis and cancer stem cell maintenance. Repression of the non-reverse transcriptase activity of hTERT may be a new strategy for tumor therapy.
\end{abstract}

\section{Contents}

1. Introduction

2.hTERT non-reverse transcriptase activity and tumor formation

3. hTERT non-reverse transcriptase activity and tumor metastasis

Correspondence to: Professor Shi-Ming Yang, Department of Gastroenterology, Xinqiao Hospital, Third Military Medical University, Chongqing 400037, P.R. China

E-mail: shimingyang@yahoo.com

Abbreviations: hTERT, human telomerase reverse transcriptase; hTR, human telomerase RNA; EMT, epithelial mesenchymal transition; CSCs, cancer stem cells; mTert, mouse telomerase reverse transcriptase; hMECs, human mammary epithelial cells; APL, acute promyelocytic leukemia; TNF, tumor necrosis factor; TRAIL, TNF-related apoptosisinducing ligand; ATRA, all-trans retinoic acid; DDR, DNA damage response; RMRP, RNA processing endoribonucleases; ROS, reactive oxygen species; BRG1, brahma-related gene 1; NS, nucleostemin; ALT, alternative lengthening of telomeres

Key words: human telomerase reverse transcriptase, non-reverse transcriptase activity
4. hTERT non-reverse transcriptase activity and maintenance of cancer stem cells

5.hTERT non-reverse transcriptase activity and clinical application

6. Perspectives and Conclusion

\section{Introduction}

Telomerase is a reverse transcriptase that carries its own template and synthesizes DNA telomere repeats to maintain telomere length. These repeats are composed of 1000-2000 non-coding tandem repeats of the TTAGGG sequence and serve as protective 'caps' at the ends of chromosomes, protecting the chromosomes from degradation and thereby maintaining chromosome stability, enhancing cell proliferation and promoting cell immortality (1-5). In most cell types, after each round of DNA replication, the telomeres are shortened. However, telomere length is stabilized by the telomerase enzyme in some stem cells, and telomerase activation is a very common occurrence in tumor cells (6-9). In humans, the active telomerase is composed of two components: i) human telomerase RNA (hTR), which contains the template for reverse transcription and is expressed in most cells; and ii) human telomerase reverse transcriptase (hTERT), which is a reverse transcriptase that catalytically synthesizes telomere DNA. hTERT expression seems to be restricted to telomerase-positive tissues, which indicates that hTERT is the limiting factor for telomerase activity (10-13). Recently, evidence was shown that hTERT alone is sufficient to restore telomerase activity and this restoration results in tumorigenesis in telomerase negative cells, such as epithelial cells and human fibroblasts (14-16). Tumors express high levels of hTERT (80-90\%) (17), suggesting that the reverse transcriptase activity of hTERT plays an important role in tumor occurrence and development.

Most research on hTERT has been focused on its crucial function of telomere maintenance. However, there are many phenomena that cannot be explained by its reverse transcriptase activity. Recent research has discovered that hTERT has other functions unrelated to its reverse transcriptase activity, such as increasing the anti-apoptotic capacity of cells, enhancing DNA repair, maintaining stem cells and regulating gene expression (18). Non-canonical roles of hTERT have also been revealed (19). These non-canonical roles of hTERT are 
referred to as its non-reverse transcriptase activity. We review the role and mechanisms of the non-reverse transcriptase activity of hTERT in tumor progression.

\section{2. hTERT non-reverse transcriptase activity and tumor formation}

Cellular immortalization is recognized as a major hallmark of cancer and it is generally accepted as a necessary step in the cancer initiation process (20). Mounting evidence suggests that telomerase plays an important role in cellular immortalization and oncogenesis. The number of telomeres determines the proliferative capacity of the cell and hTERT plays a key role in maintaining telomere length. Cellular senescence is due to telomere shortening, and immortalization strategies typically include forced expression of hTERT (21). In a mouse model, mouse telomerase reverse transcriptase (mTert) could immortalize wild-type (WT) and Nmp4-deletion bone marrow stromal cells, causing them to exhibit sustained growth. In other mammals and in humans, expression of exogenous hTERT in bone marrow mesenchymal stem cells (MSCs) resulted in immortalization (22-26). A recent study indicated that introduction of hTERT alone was sufficient for the immortalization of human mammary epithelial cells (hMECs) grown in specialized media (27).

These previous studies demonstrate that cellular immortalization is a result of hTERT extending telomere length through its reverse transcriptase activity and telomere maintenance is an important aspect of the biological process of immortalization. Nonetheless, recent data have shown that the reverse transcriptase activity of hTERT is not necessary for cell proliferation and immortalization. Stewart et al showed that ectopic expression of hTERT in the GM847 immortal cell line imparted a tumorigenic phenotype. This outcome was also observed after introduction of a mutant hTERT that was incapable of maintaining telomere length. This indicates that hTERT has an additional function that is required for tumorigenesis but does not depend on its ability to maintain telomeres (28).

In 2004, it was shown that in a maturation-resistant acute promyelocytic leukemia (APL) cell line, overexpression of hTERT imparted protection from apoptosis induced by tumor necrosis factor (TNF) or TNF-related apoptosis-inducing ligand (TRAIL) following all-trans retinoic acid (ATRA) treatment, and this function was independent of telomerase activity on telomeres (29). Beliveau et al found that the enhanced cell proliferation ability of HMECs after hTERT overexpression does not rely on its reverse transcriptase function, but on its ability to modulate the DNA damage response (DDR), which in turn suppresses apoptosis (30). These findings provide a previously unknown mechanistic explanation for the observation that exogenously expressed hTERT offers growth advantages to cells without the basic functions of its enzyme activity, indicating that hTERT has growth regulatory properties independent of its role in telomere maintenance.

hTERT has also been shown to be involved in mitochondrial apoptosis induced by targeted inhibition of Bcl-2. In addition, hTERT mutants, which are catalytically and biologically inactive, showed similar behavior as the wild-type form, indicating that hTERT inhibited apoptosis regardless of its telomerase activity and its ability to lengthen telomeres (31). hTERT has also been found to activate Wnt signaling, therefore causing target genes to promote cell proliferation and induce carcinogenesis in normal epithelia $(32,33)$. Carcinogenesis was chemically induced in TERT-positive and TERT-negative mice and their risk of skin cancer was analysed. The mice with high levels of TERT expression had a significantly higher risk of skin cancer than the hTERT-negative mice, but the length of their telomeres was not changed (34). Mukherjee et al found that the ability of the hTERT to enhance cell proliferation can be uncoupled not only from telomere elongation but also from other telomerase activities. The cellular lifespan extension was found to be due to hTERT regulating DNA damage responses (Fig. 1A) and reducing RNA processing endoribonucleases (RMRP) (35). hTERT can also alleviate basal cellular reactive oxygen species (ROS) levels by potentiating the cellular antioxidant defense systems, (Fig. 1B), thus allowing cancer cells to evade death stimuli (36).

The data presented here, together with other recent evidence underscore that there are broad biological consequences of hTERT expression aside from its essential function in telomere maintenance. The non-reverse transcriptase activity of hTERT plays a very important role in tumor formation; this effect is independent of the reverse transcriptase activity of hTERT, and telomere extension is not necessary for cell immortalization and tumor formation.

\section{3. hTERT non-reverse transcriptase activity and tumor metastasis}

If superior proliferation ability is the main feature of early primary tumors, then metastasis is the main feature of endstage cancer. Metastasis directly threatens the lives of cancer patients and is the cause of $90 \%$ of cancer deaths (37). The multi-step process of tumor invasion and metastasis, referred to as the invasion-metastasis cascade, includes loss of cellular adhesion, increased motility, entry into and survival in the circulation, exit into new tissue and eventual colonization at a distant site $(38,39)$. Tumor invasion and metastasis are associated with a variety of factors and processes, including: the epithelial mesenchymal transition (EMT), heterotypic contributions of stromal cells and plasticity in the invasive growth program. EMT plays a critical role in cancer metastatic progression and it has been postulated to be an absolute requirement for tumor invasion and metastasis (40-43). EMT refers to the physiological and pathological situations occurring during cell epithelial-mesenchymal transition, accompanied by cell morphology and gene expression changes. It is characterized by the loss of epithelial proteins, including E-cadherin, $\gamma$-catenin and $\beta$-catenin, and is often accompanied by the increase of mesenchymal proteins such as vimentin, fibronectin and smooth muscle actin $(19,44)$.

E-cadherin expression is a marker of epithelial cells and it is an initiating factor for EMT. The downregulation, inhibition, or loss of function of E-cadherin can activate EMT. E-cadherin also helps maintain cancer cell adhesion to prevent tumor invasion and metastasis. A variety of factors have been shown to regulate E-cadherin, including somatic mutations, promoter hypermethylation, the Snail protein and the ZEB family (45). 

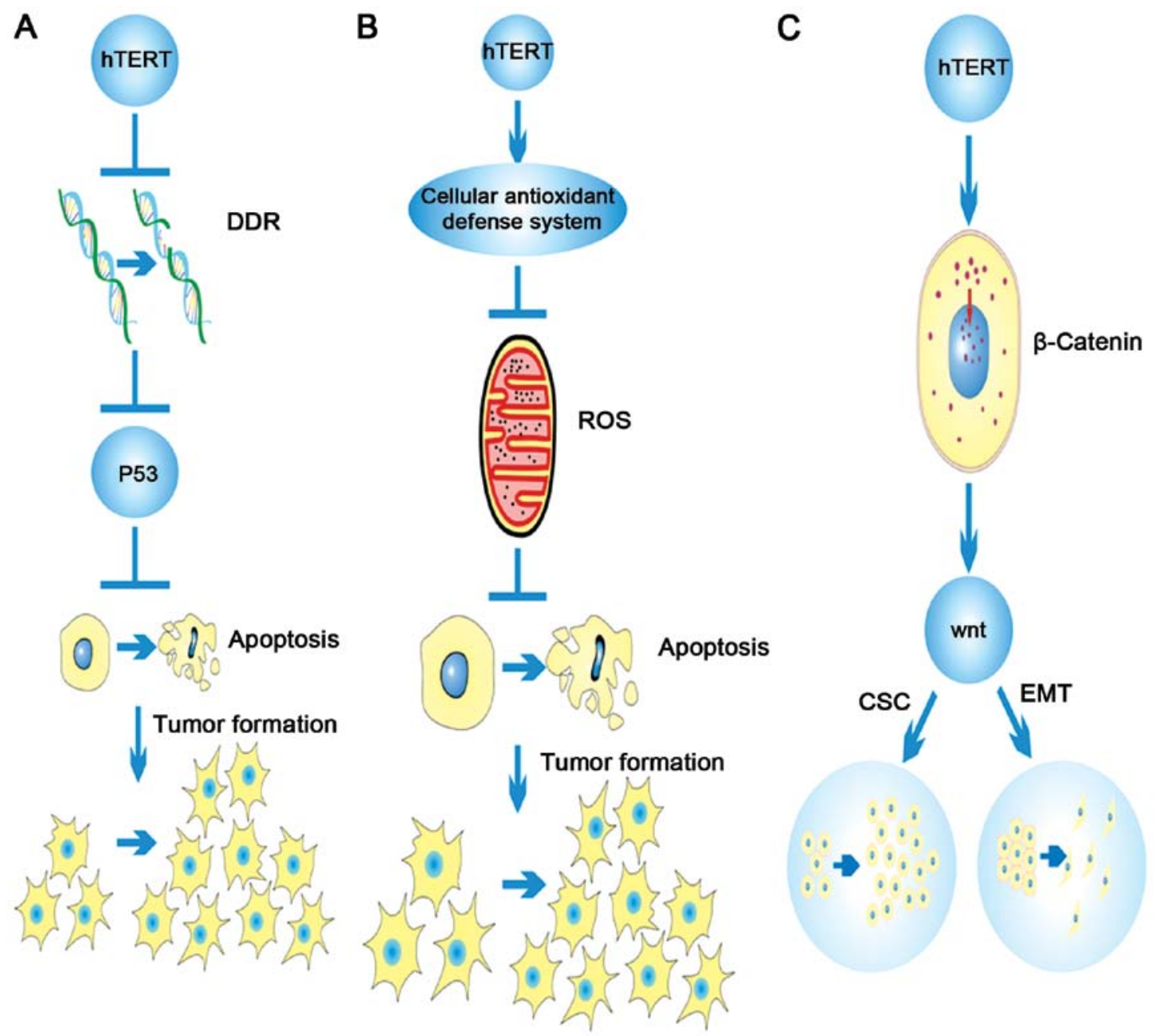

Figure 1. Main function of non-reverse transcriptase activity of the human telomerase reverse transcriptase (hTERT). (A) hTERT represses the DDR to repress the 53 expression and help cells escape apoptosis, finally inducing tumor formation. (B) hTERT through cellular antioxidant defense systems downregulates the ROS level to promote tumor proliferation. (C) hTERT helps $\beta$-catenin to enter the cytoblasts and activate the Wnt signal pathway to maintain cancer stem cells (CSC) inducing EMT.

Evidence shows that hTERT can promote the metastasis of cells and this capability may be independent of its nonreverse transcriptase activity. Upon hTERT transfection into U2OS osteosarcoma cells, a telomerase-negative cell line, the invasion and metastasis of tumor cells were increased (46). In human esophageal squamous cell cancer, hTERT activation increased migration and invasion when compared with control cells. It has been shown that hTERT regulates the glycolytic pathway in melanoma cells, improving the energy supply state of the tumor cells thus contributing to tumor invasion and metastasis $(47,48)$. Recent studies have indicated that exogenous expression of hTERT also leads to upregulation of MMP9 and RhoC and promotes the invasiveness and metastasis of HepG2 cells in vitro (49).

hTERT promotes not only tumor formation, but also tumor metastasis. Therefore, it is possible that hTERT promotes tumor metastasis through the EMT pathway. Transfection of TERT into Xenopus caused faster embryonic limb and neuron development compared to controls, and promoting embryonic development is one of the three main functions of EMT, which also plays a central role in embryogenesis $(32,40,50)$. It has also been demonstrated that hTERT can affect TGF- $\beta 1$ - mediated $\beta$-catenin induction and nuclear accumulation, which enhances Wnt signaling pathway activation and promotes EMT (51) (Fig. 1C). hTERT can form a complex with the brahma-related gene 1 (BRG1) and nucleostemin (NS) through upregulation of Twist to increase EMT and this complex does not directly contribute to telomere maintenance (52) (Fig. 1C). In summary, hTERT plays a role in tumor invasion and metastasis by promoting EMT and this function is independent of its reverse transcriptase activity.

\section{4. hTERT non-reverse transcriptase activity and maintenance of cancer stem cells}

In recent years, the theory of cancer stem cells (CSCs) has provided a more reasonable explanation for the formation and recurrence of malignant tumor metastasis and chemotherapy resistance. CSCs are a subset of tumor cells that have the ability to self-renew and generate the diverse cells that form the tumor $(53,54)$. Evidence suggests that most solid tumors are hierarchically organized and sustained by CSCs (55). Some scholars believe that the existence of CSCs leads to the failure of cancer treatment. Therefore, studying the mechanisms of 
regulation of CSCs and targeting CSCs for therapy may be a promising area for finding a cure for cancer (56). Park et al showed that transduction of hTERT, SV40 large T antigen and four transcription factors (OCT4, SOX2, MYC and KLF4) resulted in a higher frequency of human pluripotent stem (iPS) cell colony formation (57). A study showed that human mammary progenitor cells rendered immortal using hTERT retain both self-renewal and differentiation capacity along the luminal and myoepithelial lineages (58). It is known that EMT and CSCs have some common features, EMT generates cancer cells with stem cell-like characteristics; stem-like cells express markers associated with EMT; and the diversity and abundance of CSCs in solid tumors allows cells the ability to undergo EMT. Mainly by non-cancer stem cells, but under certain conditions non-tumor stem cells can also adopt cancer stem cell characteristics via EMT $(43,59-61)$.

Because hTERT can promote EMT through its non-reverse transcriptase activity, it may contribute to CSC maintenance. CD133, a marker of CSCs, was found to be more highly expressed in hTERT-immortalized cells than in primary prostate cells. Stem cell properties were increased when SV40ER and hTERT were introduced into breast cancer cells $(62,63)$. Castelo-Branco et al found that CSCs had significantly higher levels of hTERT expression than normal tissue stem cells, but Southern blot analysis revealed that CSCs had extremely short telomeres compared with the normal tissue stem cells (64). In a gastric cancer (GC) model, hTERT has been shown to induce stem-like activity of cancer cells, and this activity is independent of its telomere-lengthening function (51). Further research defines a complex composed of TERT, BRG1 and NS that maintains the function of CSCs, and this interaction is independent of telomerase activity (52). Wnt signaling activity functionally designates the colon CSC population and is a marker for colon CSCs. As described previously, hTERT can activate the Wnt signaling pathway. Therefore, hTERT regulates tumor stem cell maintenance through the Wnt signaling pathway $(32,65)$ (Fig. 1C). The above data demonstrate that hTERT contributes to the maintenance of CSCs through its non-reverse transcriptase activity.

\section{5. hTERT non-reverse transcriptase activity and clinical application}

It is known that the majority of tumor cells express high levels of hTERT and that normal somatic cells do not express hTERT. Therefore, telomerase has been considered as a tumor marker and an attractive target for anticancer therapy for many types of cancer (66). When the hTERT promoter is replaced by an adenoviral promoter to construct cytolytic adenovirus, it can efficiently infect tumor cells and significantly inhibit the growth of hepatoma cells. Experiments in nude mice showed that this adenovirus can reduce the formation of tumor nodules by lung cancer cells, and this was associated with low liver toxicity (67). In addition, because of the tumor-specific expression of hTERT, some researchers believe that hTERT is a tumor-associated antigen. Studies have shown that hTERT fragments act as antigens in mice, and $\mathrm{CD}^{+}$and $\mathrm{CD}^{+}$are stimulated for expansion $(68,69)$. GV1001, which is a 16 -amino acid MHC class II-restricted hTERT peptide vaccine, consists of amino acids 611-626 (EARPALLTSRLRFIPK) of the
hTERT active site (70,71). GV1001 has shown good antitumor efficacy in patients in phase I and II clinical trials $(72,73)$. In addition, a potent hTERT inhibitor 2-[(E)-3-naphthalene-2yl-but-2-enoylamino]-benzoic acid (BIBR1532) specifically blocks the elongation of telomerase DNA, therefore resulting in cellular senescence and inhibition of proliferation (74,75).

Because hTERT promoter regulation very tightly controls telomerase activity, directly targeting the hTERT promoter may be an effective method for tumor therapy $(76,77)$. When telomerase-positive cells were treated with an hTERT-driven prodrug-activating enzyme which could repress the hTERT promoter, the cells became apoptotic (78-80). However, targeting hTERT has some problems: i) hTERT activity may not be detected in the whole of the tumor, therefore it may not be sensitive to targeted therapy; ii) When hTERT is inhibited, the telomere length shortens over a period of time and tumor apoptosis may have a lag; iii) Despite inhibition of hTERT reverse transcriptase activity, some tumors evade apoptosis through other mechanisms, such as using the alternative lengthening of telomeres (ALT) pathway or activating mitochondrial adaptive mechanisms $(81,82)$.

Targeting the non-reverse transcriptase activity of hTERT may solve the problems noted above. First, the hTERT nonreverse transcriptase activity is unrelated to its telomerase activity, so if the cell has no telomerase activity, the hTERT non-reverse transcriptase activity can be targeted for tumor therapy. Second, because targeting the non-reverse transcriptase activity of hTERT does not shorten telomere length, there would be no lag effect. Finally, targeting the hTERT nonreverse transcriptase activity will not activate other pathways that promote tumor proliferation and metastasis. Telomerase immunotherapy is currently an area of active research focus. Therapeutic resistance is an issue to be considered, especially because of the existence of ALT mechanisms to maintain telomeres (83). Inhibition of the non-reverse transcriptase activity of hTERT for anticancer therapy can be used as a supplement for telomerase therapy and may even completely replace it in some tumors.

\section{Perspectives and Conclusion}

Telomerase plays an important role in the maintenance, protection and stabilization of chromosomes, but these diverse roles can lead to opportunities for cancers to activate hTERT reverse transcriptase activity during tumorigenesis and escape cell senescence (84). Most cancer cells express hTERT, underscoring the importance of efforts to understand its mechanisms of regulation, its implications for cell survival and cancer therapy resistance, and its interaction with other signaling pathways.

In recent years, studying the reverse transcriptase activity of hTERT has been a prime research area and inhibition of telomerase activity has become a popular treatment. hTERT expression provides valuable information for early tumor diagnosis, staging and prognosis. However, some studies show that hTERT has novel functions that are independent of its reverse transcriptase activity. These include inducing tumor formation, increasing cell proliferation, promoting tumor metastasis and maintaining CSCs. These new findings will allow us to better understand the function of hTERT, and its alternative 
functions help clarify the unexplained phenomena that are not due to its reverse transcriptase activity.

The hTERT non-reverse transcriptase activity mechanism will open up new avenues for tumor therapy. Inhibition of hTERT non-reverse transcriptase activity has the potential to be an efficient and low toxicity method of cancer treatment. However, hTERT activity and its regulatory mechanisms and pathways are complex and diverse. Therefore, we still face many problems and challenges. Research on the non-reverse transcriptase activity of hTERT is still in its early stages, and there are many unanswered questions remaining, such as how the non-reverse transcriptase activity of hTERT affects tumor occurrence, proliferation, metastasis and CSC maintenance. Its mechanisms will require further study. For example, it is unknown whether the non-reverse transcriptase activity of hTERT is involved in normal cell division and proliferation, stem cell differentiation and embryonic development. The hTERT non-reverse transcriptase activity promotes tumor development through multiple mechanisms, so the development of targeted therapy is a complex issue that merits further study.

In summary, there is mounting evidence that hTERT has different roles when it associates with different factors or is targeted to different cellular locations away from telomeres. New functions of hTERT are only beginning to be elucidated. We plan to further study the non-reverse transcriptase activity of hTERT and determine its pro-cancer development mechanism and how it can be therapeutically targeted. We hope this research would help improve the efficiency of cancer treatment, reduce drug doses to lower the cytotoxicity in normal cells and eventually lead to a cancer cure.

\section{Acknowledgements}

This work was supported by the National Nature Science Foundation of China (No. 81272689).

\section{References}

1. Liu L, Lai S, Andrews G and Tollefsbol TO: Genetic and epigenetic modulation of telomerase activity in development and disease. Gene 340: 1-10, 2004.

2. Liu L, Saldanha SN, Pate MS, Andrews LG and Tollefsbol TO: Epigenetic regulation of human telomerase reverse transcriptase promoter activity during cellular differentiation. Genes Chromosomes Cancer 41: 26-37, 2004.

3. Blackburn EH: Switching and signaling at the telomere. Cell 106: 661-673, 2001.

4. Blackburn EH: Telomerase and cancer: Kirk A. Landon - AACR prize for basic cancer research lecture. Mol Cancer Res 3: 477-482, 2005

5. Blackburn EH, Greider CW and Szostak JW: Telomeres and telomerase: the path from maize, Tetrahymena and yeast to human cancer and aging. Nat Med 12: 1133-1138, 2006.

6. Kim NW, Piatyszek MA, Prowse KR, Harley CB, West MD, Ho PL, Coviello GM, Wright WE, Weinrich SL and Shay JW: Specific association of human telomerase activity with immortal cells and cancer. Science 266: 2011-2015, 1994.

7. Shay JW, Zou Y, Hiyama E and Wright WE: Telomerase and cancer. Hum Mol Genet 10: 677-685, 2001.

8. Greider CW: Telomerase activation. One step on the road to cancer? Trends Genet 15: 109-112, 1999.

9. Nugent CI and Lundblad V: The telomerase reverse transcriptase: components and regulation. Genes Dev 12: 1073-1085, 1998.

10. Feng J, Funk WD, Wang SS, Weinrich SL, Avilion AA, Chiu CP, Adams RR, Chang E, Allsopp RC and Yu J: The RNA component of human telomerase. Science 269: 1236-1241, 1995.
11. Nakamura TM, Morin GB, Chapman KB, Weinrich SL, Andrews WH, Lingner J, Harley CB and Cech TR: Telomerase catalytic subunit homologs from fission yeast and human. Science 277: 955-959, 1997.

12. Smogorzewska A and de Lange T: Regulation of telomerase by telomeric proteins. Annu Rev Biochem 73: 177-208, 2004.

13. Chang JT, Chen YL, Yang HT, Chen CY and Cheng AJ: Differential regulation of telomerase activity by six telomerase subunits. Eur J Biochem 269: 3442-3450, 2002.

14. Qi DL, Ohhira T, Fujisaki C, Inoue T, Ohta T, Osaki M, Ohshiro E, Seko T, Aoki S and Oshimura M: Identification of PITX1 as a TERT suppressor gene located on human chromosome 5. Mol Cell Biol 31: 1624-1636, 2011.

15. Gonzalez-Suarez E, Flores JM and Blasco MA: Cooperation between 553 mutation and high telomerase transgenic expression in spontaneous cancer development. Mol Cell Biol 22: 291-301, 2002.

16. Hahn WC, Counter CM, Lundberg AS, Beijersbergen RL, Brooks MW and Weinberg RA: Creation of human tumour cells with defined genetic elements. Nature 400: 464-468, 1999.

17. Harley CB: Telomerase and cancer therapeutics. Nat Rev Cancer 8: 167-179, 2008.

18. Cong Y and Shay JW: Actions of human telomerase beyond telomeres. Cell Res 18: 725-732, 2008.

19. Hanahan D and Weinberg RA: Hallmarks of cancer: the next generation. Cell 144: 646-674, 2011.

20. Kan CY, Wen VW, Pasquier E, Jankowski K, Chang M, Richards LA, Kavallaris M and MacKenzie KL: Endothelial cell dysfunction and cytoskeletal changes associated with repression of p16(INK4a) during immortalization. Oncogene 31: 4815-4827, 2012.

21. Tátrai P, Szepesi Á, Matula Z, Szigeti A, Buchan G, Mádi A, Uher $F$ and Német K: Combined introduction of Bmi-1 and hTERT immortalizes human adipose tissue-derived stromal cells with low risk of transformation. Biochem Biophys Res Commun 422: 28-35, 2012

22. Simonsen JL, Rosada C, Serakinci N, Justesen J, Stenderup K, Rattan SI, Jensen TG and Kassem M: Telomerase expression extends the proliferative life-span and maintains the osteogenic potential of human bone marrow stromal cells. Nat Biotechnol 20: 592-596, 2002.

23. Gao K,Lu YR, Wei LL, Lu XF,Li SF, Wan L,Li YP and Cheng JQ: Immortalization of mesenchymal stem cells from bone marrow of rhesus monkey by transfection with human telomerase reverse transcriptase gene. Transplant Proc 40: 634-637, 2008.

24. Huang GP, Pan ZJ, Huang JP, Yang JF, Guo CJ, Wang YG, Zheng Q, Chen R, Xu YL, Wang GZ, Xi YM, Shen D, Jin J and Wang JF: Proteomic analysis of human bone marrow mesenchymal stem cells transduced with human telomerase reverse transcriptase gene during proliferation. Cell Prolif 41: 625-644, 2008.

25. Wei LL, Gao K, Liu PQ, Lu XF, Li SF, Cheng JQ, Li YP and Lu YR: Mesenchymal stem cells from Chinese Guizhou minipig by hTERT gene transfection. Transplant Proc 40: 547-550, 2008.

26. Alvarez MB, Childress P, Philip BK, Gerard-O'Riley R, Hanlon M, Herbert BS, Robling AG, Pavalko FM and Bidwell JP: Immortalization and characterization of osteoblast cell lines generated from wild-type and Nmp4-null mouse bone marrow stromal cells using murine telomerase reverse transcriptase (mTERT). J Cell Physiol 227: 1873-1882, 2012.

27. Zhao XS, Malhotra GK, Lele SM, Lele MS, West WW, Eudy JD, Band $\mathrm{H}$ and Band $\mathrm{V}$ : Telomerase-immortalized human mammary stem/progenitor cells with ability to self-renew and differentiate. Proc Natl Acad Sci USA: 14146-14151, 2010.

28. Stewart SA, Hahn WC, O'Connor BF, Banner EN, Lundberg AS, Modha P, Mizuno H, Brooks MW, Fleming M, Zimonjic DB, Popescu NC and Weinberg RA: Telomerase contributes to tumorigenesis by a telomere length-independent mechanism. Proc Natl Acad Sci USA: 12606-12611, 2002.

29. Dudognon C, Pendino F, Hillion J, Saumet A, Lanotte M and Ségal-Bendirdjian E: Death receptor signaling regulatory function for telomerase: hTERT abolishes TRAIL-induced apoptosis, independently of telomere maintenance. Oncogene 23: 7469-7474, 2004.

30. Beliveau A, Bassett E, Lo AT, Garbe J, Rubio MA, Bissell MJ, Campisi $\mathrm{J}$ and Yaswen P: p53-dependent integration of telomere and growth factor deprivation signals. Proc Natl Acad Sci USA 104: 4431-4436, 2007.

31. Del Bufalo D, Rizzo A, Trisciuoglio D, Cardinali G, Torrisi MR, Zangemeister-Wittke U, Zupi G and Biroccio A: Involvement of hTERT in apoptosis induced by interference with Bcl-2 expression and function. Cell Death Differ 12: 1429-1438, 2005. 
32. Park JI, Venteicher AS, Hong JY, Choi J, Jun S, Shkreli M, Chang W, Meng Z, Cheung P, Ji H, McLaughlin M, Veenstra TD, Nusse R, McCrea PD and Artandi SE: Telomerase modulates Wnt signalling by association with target gene chromatin. Nature 460: 66-72, 2009.

33. Choi JK, Southworth LK, Sarin KY, Venteicher AS, Ma WX, Chang W, Cheung P, Jun SH, Artandi MK and Shah N: TERT promotes epithelial proliferation through transcriptional control of a Myc- and Wnt-related developmental program. PLoS Genet 4: e10, 2008.

34. González-Suárez E, Samper E, Ramírez A, Flores JM, MartínCaballero J, Jorcano JL and Blasco MA: Increased epidermal tumors and increased skin wound healing in transgenic mice overexpressing the catalytic subunit of telomerase, mTERT, in basal keratinocytes. EMBO J 20: 2619-2630, 2001

35. Mukherjee S, Firpo EJ, Wang Y and Roberts JM: Separation of telomerase functions by reverse genetics. Proc Natl Acad Sci USA 108: 1363-1371, 2011.

36. Indran IR, Hande MP and Pervaiz S: hTERT overexpression alleviates intracellular ROS production, improves mitochondrial function, and inhibits ROS-mediated apoptosis in cancer cells. Cancer Res 71: 266-276, 2011.

37. Gupta GP and Massague J: Cancer metastasis: building a framework. Cell 127: 679-695, 2006.

38. Talmadge JE and Fidler IJ: AACR centennial series: the biology of cancer metastasis: historical perspective. Cancer Res 70 : 5649-5669, 2010.

39. Fidler IJ: The pathogenesis of cancer metastasis: the 'seed and soil' hypothesis revisited. Nat Rev Cancer 3: 453-458, 2003.

40. Kalluri R and Weinberg RA: The basics of epithelial-mesenchymal transition. J Clin Invest 119: 1420-1428, 2009.

41. Thiery JP, Acloque H, Huang RY and Nieto MA: Epithelialmesenchymal transitions in development and disease. Cell 139: 871-890, 2009.

42. Tsuji T, Ibaragi S and Hu GF: Epithelial-mesenchymal transition and cell cooperativity in metastasis. Cancer Res 69: 7135-7139, 2009.

43. Polyak K and Weinberg RA: Transitions between epithelial and mesenchymal states: acquisition of malignant and stem cell traits. Nat Rev Cancer 9: 265-273, 2009

44. Huber MA, Kraut N and Beug H: Molecular requirements for epithelial-mesenchymal transition during tumor progression. Curr Opin Cell Biol 17: 548-558, 2005.

45. Berx G and van Roy F: Involvement of members of the cadherin superfamily in cancer. Cold Spring Harb Perspect Biol 1: a003129, 2009.

46. Yu ST, Chen L, Wang HJ, Tang XD, Fang DC and Yang SM hTERT promotes the invasion of telomerase-negative tumor cells in vitro. Int J Oncol 35: 329-336, 2009.

47. Okawa T, Michaylira CZ, Kalabis J, Stairs DB, Nakagawa H, Andl CD, Johnstone CN, Klein-Szanto AJ, El-Deiry WS and Cukierman E: The functional interplay between EGFR overexpression, hTERT activation, and p53 mutation in esophageal epithelial cells with activation of stromal fibroblasts induces tumor development, invasion, and differentiation. Genes Dev 21: 2788-2803, 2007.

48. Bagheri S, Nosrati M,Li S, Fong S, Torabian S, Rangel J, Moore DH, Federman S, Laposa RR, Baehner FL, Sagebiel RW, Cleaver JE, Haqq C, Debs RJ, Blackburn EH and Kashani-Sabet M: Genes and pathways downstream of telomerase in melanoma metastasis. Proc Natl Acad Sci USA 103: 11306-11311, 2006.

49. Chen PC, Peng JR, Huang L, Li WX, Wang WZ, Cui ZQ, Han H, Gong L, Xiang DP, Qiao SS, Yu X, Wei YH, Ma LP, Li N, Zhu JY and Leng XS: Overexpression of human telomerase reverse transcriptase promotes the motility and invasiveness of HepG2 cells in vitro. Oncol Rep 30: 1157-1164, 2013

50. Thiery JP and Sleeman JP: Complex networks orchestrate epithelial-mesenchymal transitions. Nat Rev Mol Cell Biol 7: 131-142, 2006

51. Liu Z, Li Q, Li K, Chen L, Li W, Hou M, Liu T, Yang J,Lindvall C, Björkholm M, Jia J and Xu D: Telomerase reverse transcriptase promotes epithelial-mesenchymal transition and stem cell-like traits in cancer cells. Oncogene 32: 4203-4213, 2012.

52. Okamoto N, Yasukawa M, Nguyen C, Kasim V, Maida Y, Possemato R, Shibata T, Ligon KL, Fukami K, Hahn WC and Masutomi K: Maintenance of tumor initiating cells of defined genetic composition by nucleostemin. Proc Natl Acad Sci USA 108: 20388-20393, 2011.

53. Clarke MF, Dick JE, Dirks PB, Eaves CJ, Jamieson CH, Jones DL, Visvader J, Weissman IL and Wahl GM: Cancer stem cells - perspectives on current status and future directions: AACR Workshop on cancer stem cells. Cancer Res 66: 9339-9344, 2006.
54. Guo W, Lasky JL and Wu H: Cancer stem cells. Pediatr Res 59: 59-64, 2006.

55. Visvader JE and Lindeman GJ: Cancer stem cells in solid tumours: accumulating evidence and unresolved questions. Nat Rev Cancer 8: 755-768, 2008.

56. Xia J, Chen C, Chen Z, Miele L, Sarkar FH and Wang Z: Targeting pancreatic cancer stem cells for cancer therapy. Biochim Biophys Acta 1826: 385-399, 2012

57. Park IH, Zhao R, West JA, Yabuuchi A, Huo H, Ince TA, Lerou PH, Lensch MW and Daley GQ: Reprogramming of human somatic cells to pluripotency with defined factors. Nature 45: 141-146, 2008.

58. Zhao X, Malhotra GK, Band $\mathrm{H}$ and Band V: A block in lineage differentiation of immortal human mammary stem/progenitor cells by ectopically-expressed oncogenes. J Carcinog 10: 39, 2011.

59. Mani SA, Guo W, Liao MJ, Eaton EN, Ayyanan A, Zhou AY, Brooks M, Reinhard F, Zhang CC, Shipitsin M, Campbell LL, Polyak K, Brisken C, Yang J and Weinberg RA: The epithelialmesenchymal transition generates cells with properties of stem cells. Cell 133: 704-715, 2008.

60. Rosen JM and Jordan CT: The increasing complexity of the cancer stem cell paradigm. Science 324: 1670-1673, 2009.

61. Morel AP, Lièvre M, Thomas C, Hinkal G, Ansieau S and Puisieux A: Generation of breast cancer stem cells through epithelial-mesenchymal transition. PLoS One 3: e2888, 2008.

62. Miki J, Furusato B, Li H, Gu Y, Takahashi H, Egawa S, Sesterhenn IA, McLeod DG, Srivastava S and Rhim JS: Identification of putative stem cell markers, CD133 and CXCR4, in hTERT-immortalized primary nonmalignant and malignant tumor-derived human prostate epithelial cell lines and in prostate cancer specimens. Cancer Res 67: 3153-3161, 2007.

63. Paranjape AN, Mandal T, Mukherjee G, Kumar MV, Sengupta K and Rangarajan A: Introduction of SV40ER and hTERT into mammospheres generates breast cancer cells with stem cell properties. Oncogene 31: 1896-1909, 2011.

64. Castelo-Branco P, Zhang C, Lipman T, Fujitani M, Hansford L, Clarke I, Harley CB, Tressler R, Malkin D, Walker E, Kaplan DR, Dirks P and Tabori U: Neural tumor-initiating cells have distinct telomere maintenance and can be safely targeted for telomerase inhibition. Clin Cancer Res 17: 111-121, 2011.

65. Vermeulen L, De Sousa E Melo F, van der Heijden M, Cameron K, de Jong JH, Borovski T, Tuynman JB, Todaro M, Merz C, Rodermond H, Sprick MR, Kemper K, Richel DJ, Stassi G and Medema JP: Wnt activity defines colon cancer stem cells and is regulated by the microenvironment. Nat Cell Biol 12: 468-476, 2010.

66. Lü MH, Liao ZL, Zhao XY, Fan YH, Lin XL, Fang DC, Guo H and Yang SM: hTERT-based therapy: a universal anticancer approach (Review). Oncol Rep 28: 1945-1952, 2012.

67. Kuppuswamy M, Spencer JF, Doronin K, Tollefson AE, Wold WS and Toth K: Oncolytic adenovirus that overproduces ADP and replicates selectively in tumors due to hTERT promoter-regulated E4 gene expression. Gene Ther 12: 1608-1617, 2005.

69. Liu JP, Chen W, Schwarer AP and Li H: Telomerase in cancer immunotherapy. Biochim Biophys Acta 1805: 35-42, 2010.

69. Nair SK, Heiser A, Boczkowski D, Majumdar A, Naoe M, Lebkowski JS, Vieweg J and Gilboa E: Induction of cytotoxic $\mathrm{T}$ cell responses and tumor immunity against unrelated tumors using telomerase reverse transcriptase RNA transfected dendritic cells. Nat Med 6: 1011-1017, 2000.

70. Kyte JA: Cancer vaccination with telomerase peptide GV1001. Expert Opin Investig Drugs 18: 687-694, 2009.

71. Nava-Parada P and Emens LA: GV-1001, an injectable telomerase peptide vaccine for the treatment of solid cancers. Curr Opin Mol Ther 9: 490-497, 2007.

72. Mavroudis D, Bolonakis I, Cornet S, Myllaki G, Kanellou P, Kotsakis A, Galanis A, Nikoloudi I, Spyropoulou M, Menez J, Miconnet I, Niniraki M, Cordopatis P, Kosmatopoulos K and Georgoulias V: A phase I study of the optimized cryptic peptide TERT $(572 y)$ in patients with advanced malignancies. Oncology 70: 306-314, 2006

73. Menez-Jamet J and Kosmatopoulos K: Development of optimized cryptic peptides for immunotherapy. IDrugs 12: 98-102, 2009.

74. Pascolo E, Wenz C, Lingner J, Hauel N, Priepke H, Kauffmann I, Garin-Chesa P, Rettig WJ, Damm K and Schnapp A: Mechanism of human telomerase inhibition by BIBR1532, a synthetic, nonnucleosidic drug candidate. J Biol Chem 277: 15566-15572, 2002.

75. Philippi C, Loretz B, Schaefer UF and Lehr CM: Telomerase as an emerging target to fight cancer - opportunities and challenges for nanomedicine. J Control Release 146: 228-240, 2010. 
76. Cong YS, Wright WE and Shay JW: Human telomerase and its regulation. Microbiol Mol Biol Rev 66: 407-425, 2002.

77. Buseman CM, Wright WE and Shay JW: Is telomerase a viable target in cancer? Mutat Res 730: 90-97, 2012.

78. Schepelmann S, Ogilvie LM, Hedley D, Friedlos F, Martin J, Scanlon I, Chen P, Marais R and Springer CJ: Suicide gene therapy of human colon carcinoma xenografts using an armed oncolytic adenovirus expressing carboxypeptidase G2. Cancer Res 67: 4949-4955, 2007.

79. Majumdar AS, Hughes DE, Lichtsteiner SP, Wang Z Lebkowski JS and Vasserot AP: The telomerase reverse transcriptase promoter drives efficacious tumor suicide gene therapy while preventing hepatotoxicity encountered with constitutive promoters. Gene Ther 8: 568-578, 2001.

80. Zhou JH, Tang B, Liu XL, He DW and Yang DT: hTERT-targeted E. coli purine nucleoside phosphorylase gene/6-methylpurine deoxyribose therapy for pancreatic cancer. Chin Med J (Engl) 120: $1348-1352,2007$
81. Xue Y, Li L, Zhang D, Wu K, Chen Y, Zeng J, Wang X and He D: Twisted epithelial-to-mesenchymal transition promotes progression of surviving bladder cancer T24 cells with hTERTdysfunction. PLoS One 6: e27748, 2011.

82. Hu J, Hwang SS, Liesa M, Gan B, Sahin E, Jaskelioff M, Ding Z, Ying H, Boutin AT, Zhang H, Johnson S, Ivanova E, KostAlimova M, Protopopov A, Wang YA, Shirihai OS, Chin L and DePinho RA: Antitelomerase therapy provokes ALT and mitochondrial adaptive mechanisms in cancer. Cell 148: 651-663, 2012.

83. Bechter OE, Zou Y, Walker W, Wright WE and Shay JW: Telomeric recombination in mismatch repair deficient human colon cancer cells after telomerase inhibition. Cancer Res 64: 3444-3451, 2004.

84. Cukusić A, Skrobot Vidacek N, Sopta M and Rubelj I: Telomerase regulation at the crossroads of cell fate. Cytogenet Genome Res 122: $263-272,2008$. 